\title{
Comparative Study on Conservation of Agricultural Heritage Systems in China, Japan and Korea
}

\author{
YIU Evonne ${ }^{1, *}$, NAGATA Akira ${ }^{1}$, TAKEUCHI Kazuhiko ${ }^{2,3}$ \\ 1 United Nations University Institute for the Advanced Study of Sustainability (UNU-IAS), 5-53-70 Jingumae, Shibuya-ku, Tokyo 150-8925 Japan; \\ 2 United Nations University. 5-53-70 Jingumae, Shibuya-ku, Tokyo 150-8925 Japan; \\ 3 Integrated Research System for Sustainability Science, University of Tokyo. 7-3-1 Hongo, Bunkyo-ku, Tokyo 113-8654 Japan
}

\begin{abstract}
The paper compares the agricultural heritage conservation schemes of China, Japan and Korea and, in particular, the national programs and their implementation under Food and Agriculture Organization of the United Nations (FAO)'s Globally Important Agricultural Heritage Systems (GIAHS). This comparison allows an understanding of the background of developments, designation criteria, application procedures and implementation structures of GIAHS and of the respective domestic programs in terms of the differences in national circumstances of Japan, China and South Korea. The sequence of implementation of GIAHS and the national program differs in each of the three countries. China introduced a national program after GIAHS designation, Japan has GIAHS but no national program, and Korea implemented a national program before its GIAHS designation. Thus GIAHS candidate sites in China and Korea are now selected from among their respective pools of national agricultural heritage sites. On the other hand, commonalities can be seen in the perspectives of the three countries with regards to agricultural heritage conservation through the common emphasis placed on the designation criteria: historical significance, cultural value, fostering partnerships, rural revitalization and biodiversity conservation associated with the agricultural heritage systems etc. Thus, the cooperation between China, Japan and Korea and the perspectives they have will contribute to proposals for improvements to the FAO designation criteria for GIAHS. These will be comprehensively applicable to both developing and developed countries.
\end{abstract}

Key words: agricultural heritage systems; GIAHS; traditional agriculture; rural revitalization; biodiversity conservation; East Asia

\section{Introduction}

Agriculture has a long history of having to deal with famine. In an effort to counter famine, especially in developing countries, Food and Agriculture Organization of the United Nations (FAO) has used breed innovation and expansion of farmlands, as symbolized by the "Green Revolution" to actively promote increased food production to supply the global population surge. While such initiatives have achieved considerable success in increasing food supply, it is cautioned that their incompatibility and lack of harmony with local ways of life and cultures, and with biodiversity and environmental conservation efforts have also posed problems. Against this background, FAO's “Globally Im- portant Agricultural Heritage Systems (GIAHS)" initiated in 2002 was seen as an initiative to ensure that significant traditional agriculture practices would be inherited by future generations (Takeuchi and Nagata, 2015). Defined by FAO as "Remarkable land use systems and landscapes which are rich in globally significant biological diversity evolving from the co-adaptation of a community with its environment and its needs and aspirations for sustainable development", GIAHS aims to identify, support, safeguard and dynamically conserve agricultural heritage systems and the livelihoods connected with these systems, agricultural and associated biodiversity, landscapes, and knowledge systems and cultures (FAO, 2012). As of February 2016, 36 GIAHS sites in

Received: 2016-01-22 Accepted: 2016-03-20

*Corresponding author: Evonne Yiu. Email: yiu@unu.edu

Citation: YIU Evonne, NAGATA Akira, TAKEUCHI Kazuhiko. 2016. Comparative Study on Conservation of Agricultural Heritage Systems in China, Japan and Korea. Journal of Resources and Ecology. 7(3): 170-179. 
15 countries had been designated, with more than threequarters of these being concentrated in Asia and more than half of the global total located in East Asia (China 11 sites, Japan 8 sites and Korea 2 sites).

At the same time China and Korea are conserving their agricultural heritage systems through FAO GIAHS, they have also began to develop their own national designation systems (China Ministry of Agriculture, 2012; Korea Ministry for Food, Agriculture, Forestry and Fisheries, 2012). Japan also announced plans in February 2016 to introduce its own national agricultural heritage systems in the near future.

This paper will examine the designation of agricultural heritage systems by the three East Asian countries of China, Japan and Korea. The paper will compare the background of developments, designation criteria, application procedures and implementation structures of GIAHS in the three countries as well as their respective domestic programs for conserving agricultural heritage systems. The discussion will begin with China, the country with the longest period of implementation, then move to Japan and finally to Korea, the country with the shortest implementation period.

\section{GIAHS and Nationally Important Agricul- tural Heritage Systems (NIAHS) in China}

\subsection{Background of developments}

In China, the "Rice-Fish Culture System" of Qingtian County, Zhejiang Province was identified as China's first GIAHS site in the early days of the initiative. According to the Newsletter of Agricultural Heritage Systems published in 2012 by the Institute of Geographic Sciences and Natural Resources Research at the Chinese Academy of Sciences (CAS-IGSNRR), the "Inaugural Meeting of the Globally Important Agricultural Heritage Systems Project: Rice-Fish Culture System" was held from 9 to 11 June 2005 (CASIGSNRR, 2012). This can be seen as the inaugural effort of GIAHS-related activities in China. The Rice-Fish Culture System was also one of the first GIAHS pilot sites selected globally; it eventually became the first designated GIAHS site in China. More GIAHS designations for China followed "Hani Rice Terraces Systems" in Yunnan Province and "Wannian Traditional Rice Culture" in Jiangxi Province in June 2010, "Dong's Rice Fish Duck System" in Guizhou Province in August 2011, "Pu'er Traditional Tea Agrosystem" in Yunnan Province and "Aohan Dryland Farming System" in Inner Mongolia Autonomous Region in September 2012, "Kuaijishan Ancient Chinese Torreya" in Shaoxing Province and "Urban Agricultural Heritage of Xuanhua Grape Garden" in Hebei Province in May 2013, "Xinghua Duotian Agrosystem" in Jiangsu Province, "Fuzhou Jasmine and Tea Culture System" in Fujian Province and "Jiaxian
Traditional Chinese Date Gardens" in Shaanxi Province in April 2014. As of February 2016, there were 11 GIAHS sites in China, which accounts for about one-third of the total 36 GIAHS sites in 15 countries globally, making China home to more GIAHS than any other country in the world.

In March 2012, the Agricultural Products Processing Bureau of China's Ministry of Agriculture (MOA) announced in the Circular of the Ministry of Agriculture on discovering and exploiting important agricultural heritage systems of China that the development of China Nationally Important Agricultural Heritage Systems (hereafter refer as ChinaNIAHS) would commence. The designation criteria and procedures were included in documents appended to the circular (MOA, 2012). Later in July 2013, the Circular of the General Office of the Ministry of Agriculture on printing and distributing two documents as A Guide to Filing Application for Induction into List of Nationally Important Agricultural Heritage Systems (NIAHS) and A Guide to Planning of Conservation and Inheritance of Agricultural Heritage Systems were released. These made the plans more concrete by providing administrative and procedural details (MOA, 2013a). In May 2014, the Circular of the General Office of the Ministry of Agriculture on printing and distributing the Administrative Measures on Nationally Important Agricultural Heritage Systems was also announced (MOA, 2014a).

Subsequently in January 2014 the Expert Committee for GIAHS and in March 2014 the Expert Committee for China-NIAHS were established to supervise development of the initiative (MOA, 2014b) ${ }^{1}$. The first batch of 19 ChinaNIAHS systems was selected in May 2013 (MOA, 2013b), followed by announcements adding a second batch of 20 China-NIAHS in May 2014 (MOA, 2014c) and a third batch of 23 China-NIAHS in November 2015 (MOA, 2015). China had a total of 62 NIAHS as of February 2016.

\subsection{Designation criteria}

The evaluation and designation criteria for China-NIAHS are listed in the Circular of the Ministry of Agriculture on discovering and exploiting important agricultural heritage systems of China (MOA, 2012) under the "Annex I. Criteria for China Nationally Important Agricultural Heritage Systems" (Refer to Table 1). China-NIAHS selected of the basis of these criteria should include the six characteristics of active, adaptable, composite, strategic, versatile and endangered. Quantitative criteria are also stipulated; for instance, sites must have at least 100 years of history and a participation rate of more than 50 percent by inhabitants. As compared to the designation criteria of FAO, China-NIAHS also emphasizes historical value and support by inhabitants, as well as the organizational and institutional support which guarantee

\footnotetext{
1 The memberships of Expert Committee for GIAHS and the China-NIAHS Expert Committee are basically the same. The current Chairman specialises in ecology, the Deputy Chairman in grassland sciences, and other members are experts in biodiversity, plant protection, agricultural ecology, agricultural history, agricultural heritage and tea science, etc. There are a total of 27 experts of various backgrounds from the three major fields of agricultural history and culture, agricultural ecological environment, and agricultural economics.
} 
Table 1 Designation criteria for China Nationally Important Agricultural Heritage Systems

\begin{tabular}{cll}
\hline \multicolumn{1}{c}{ Category } & \multicolumn{1}{c}{ Criteria } & Features \\
\hline Basic Criteria & Historical criterion & Historical origin, length of history: \\
& Systemic criterion & $\begin{array}{l}\text { Substances and products, ecosystem services, technical knowledge and system maintenance, landscape } \\
\text { and aesthetics, spirit and culture }\end{array}$ \\
& Persistent criterion & Natural adaptation, human development \\
& Endangered criterion & Trends, stress factors \\
Secondary criteria & Demonstration criterion & Participation, accessibility, reliability \\
& Supportability criterion & Organization building, system building, preparatory planning \\
\hline
\end{tabular}

Source: "Criteria for China National Important Agricultural Heritage Systems" translated by authors

the success of the conservation and management efforts for NIAHS.

\subsection{Application procedure}

According to the Circular of the General Office of the Ministry of Agriculture on discovering and exploiting the third batch of important agricultural heritage systems of China (MOA, 2014d), the People's Governments of the respective candidate sites of the agricultural systems shall follow the instructions as stated in the above-mentioned Circular of the General Office of the Ministry of Agriculture on printing and distributing two documents as A Guide to Filing Application for Induction into List of Nationally Important Agricultural Heritage Sites (NIAHS) and A Guide to Planning of Conservation and Inheritance of Agricultural Heritage Systems, and shall prepare and submit application proposals, along with relevant documents concerning conservation and management plans to the agricultural management departments at the provincial level. Each of the provincial agricultural administrative departments will then assess the applications based on the national standards to select no more than 3 potential candidates and submit the nominations to the Leisure Agriculture Division of Agricultural Products Processing Bureau by September 2014. As for GIAHS applications, the People's Governments at the county level will follow almost the same procedure as China-NIAHS and submit their applications to MOA Department of International Cooperation International Organization Division, which is in charge of the recruitment of potential GIAHS candidate sites. While the application conditions and requirements will be based on FAO GIAHS designation criteria, the potential GIAHS candidate will be selected from the pool of existing China-NIAHS sites and, thus, indirectly, yet in fact, the China-NIAHS designation criteria will also be applied in the process of choosing the GIAHS candidate sites for China.

In China, both GIAHS and China-NIAHS place great emphasis on the cultural aspects of agricultural heritage, as reflected in its Chinese naming "zhongyao-nongye-wenhua-yichan", which literally translates as "Important Agri- cultural Culture Heritage". Thus agricultural history and culture, taken together, are both important considerations for China's GIAHS and China-NIAHS Experts Committee. Agricultural history and culture experts are highly regarded, and this aspect is a unique characteristic of China's perspective on agricultural heritage.

\subsection{Implementation structure}

The CAS-IGSNNR took the lead in the development of GIAHS in China. At the Ministry of Agriculture, GIAHS is under the supervision of the International Organization Division (Department of International Cooperation) while the Leisure Agriculture Division (Agricultural Products Processing Bureau) is responsible for China-NIAHS. For this reason, officers of the International Organization Division and CAS-IGSNNR experts represent China at international conferences for GIAHS. Similarly, the International Organization Division is in charge of the GIAHS Experts Committee while the Leisure Agriculture Division is responsible for the China-NIAHS Experts Committee. This clear separation of administrative responsibility for the promotion of global and domestic agricultural heritage is a notable characteristic of China's agricultural heritage management system.

\section{GIAHS in Japan}

\subsection{Background of developments}

In Japan, GIAHS is officially referred to as "World Agricultural Heritage" (or "seikai-nogyo-isan" in Japanese). While some civil society groups in Japan were interested in GIAHS before 2008, this did not lead to GIAHS designations. In 2009, the United Nations University (or UNU, headquarters in Tokyo) proposed the use of GIAHS for the designation of Japan's Satoyama ${ }^{2}$ to FAO GIAHS Secretariat, UNU's long-time partner in the study of agricultural diversity (agrodiversity), and to other Japanese stakeholders. In response, Hokuriku Regional Agricultural Administration Office of the Japan Ministry of Agriculture, Forestry and Fisheries (MAFF) cooperated closely with UNU to initiate a feasibility study of GIAHS in Japan (Nagata, 2011). These developments gen-

\footnotetext{
${ }^{2}$ Satoyama refers to the landscapes that feature dynamic mosaics of habitats and land uses where the harmonious interaction between people and nature maintains biodiversity while providing humans with the goods and services needed for their livelihoods, survival and well-being in a sustainable manner.
} 
erated an interest in GIAHS and the application of GIAHS began. Eventually, the Satoyama of Sado Island, Niigata Prefecture and Noto Region, Ishikawa Prefecture became the candidates for GIAHS application. In cooperation with MAFF, the local municipalities of the two prefectures each established GIAHS Promotion Associations, one for "Sado's Satoyama in Harmony with the Japanese Crested Ibis" and the other for "Noto's Satoyama and Satoumi." Both prefectures submitted proposals to FAO in December 2010. In June 2010 both applications were approved and the sites designated as GIAHS at the GIAHS International Forum held in Beijing, China. This marked the first GIAHS designations for Japan, and also the first designations of GIAHS in a developed country.

Subsequently in December 2012 "Traditional Tea-grass Integrated System in Shizuoka" of Shizuoka Prefecture and "Managing Aso Grasslands for Sustainable Agriculture" of Kumamoto Prefecture, and then in May 2013 "Kunisaki Peninsula Usa Integrated Forestry, Agriculture and Fisheries System" of Oita Prefecture, with the support and endorsement of MAFF, submitted GIAHS applications to FAO. The 3 sites were designated as GIAHS on May 29, 2015 at the GIAHS International Forum in Noto Region, Ishikawa Prefecture, Japan, the first time where the Forum was held at a GIAHS designated site.

These successful GIAHS designations increased the profile of GIAHS in Japan and stimulated interest nationwide. With the objective of ensuring smooth application of GIAHS, the GIAHS Experts Meeting was established in March 2014 (MAFF, 2014) ${ }^{3}$. After three rounds of discussions, in October 2014, the Meeting selected 3 GIAHS candidate sites for application to FAO. These 3 sites, "Ayu of Nagara River System" of Nagara River Region, Gifu Prefecture, "MinabeTanabe Ume System" of Minabe-Tanabe Region, Wakayama Prefecture and "Takachihogo-Shiibayama Mountainous Agriculture and Forestry System" of Takachihogo-Shiba Region, Miyazaki Prefecture, were then designated as GIAHS on December 15, 2015, making a total of 8 GIAHS sites in Japan as of February 2016.

\subsection{Designation criteria}

The set of "GIAHS Designation Criteria and Evaluation Perspectives" (refer to Table 2) used by the Japan GIAHS Experts Meeting was formulated based on the FAO's designation criteria, but has been further broken down in a manner that allows for more comprehensive assessments. This set of designation criteria and evaluation perspectives were developed by MAFF, based on the research outcomes of UNU's "Developing a Comprehensive Assessment Method for AgriCultural Systems in Japan" project, funded by MAFF Policy Research Institute from 2012 to 2015.
In addition, optional criteria which take into consideration perspectives from Japan's agriculture (refer to Table 3) are included: (i) environmental aspects concerning "Resilience against changes", (ii) social aspects concerning "Participation of multiple stakeholders" and (iii) economic aspects of "New business models (or sometimes referred to in Japan as "sixth industries"). As the current FAO designation criteria were intended primarily for developing countries and do not always meet the needs and situations of developed countries such as Japan, the optional criteria were proposed to offer more holistic and comprehensive assessments of GIAHS in Japan. For instance, while developing countries may be overwhelmed coping with current developmental challenges, developed countries like Japan are in a position to consider how to enhance resiliency against possible future changes. Moreover, while farmers make up the majority of rural populations in most developing countries, the rural population of Japan has relatively diversified demographics and rural areas are characterized by increasing depopulation and aging. Undertaking rural revitalization is difficult without involving various stakeholders, including such as both local and urban residents. In addition, while developing countries usually sell their unprocessed or simply processed crops to middle men or directly to the market, Japanese farmers now need to engage in processing and marketing themselves to increase their profitability. All of these serve as reasons that explain the need for optional criteria to reflect the current situation faced by agriculture in Japan. In the not too distant future, these optional criteria could be applicable to Korea, which is no longer a developing country, and also to China which faces similar aging and depopulation trends in rural areas.

\subsection{Application procedure}

The MAFF GIAHS Experts Meeting held its first meeting in April 2014 at which time the assessment methodology was discussed. UNU provided as reference materials for this meeting suggested assessment criteria and application guidelines developed based on the research outcomes from its project funded by MAFF Policy Research Institute. Subsequently, 7 applications for GIAHS were received during the submission period from May to July the same year. A second meeting was then held in September 2014, at which time experts gave the first round of assessments based on presentations made by representatives from the potential sites and determined whether assessment field visits were necessary. Following assessment field visits by the experts, a third meeting was held in October 2014 at which time three candidate sites (Gifu, Wakayama and Miyazaki prefecture) were selected based on a second round of assessments and recommended for GIAHS designation to FAO after endorsement by MAFF.

\footnotetext{
${ }^{3}$ The MAFF GIAHS Experts Meeting is comprised of seven experts, of whom two are women, with expertise in green tourism, lifestyles of health and sustainability (or LOHAS), environmental economics, UNESCO Man and the Biosphere (MAB), sustainability sciences, rural planning and fisheries.
} 


\section{Table 2 GIAHS designation criteria and evaluation perspectives (Excerpt)}

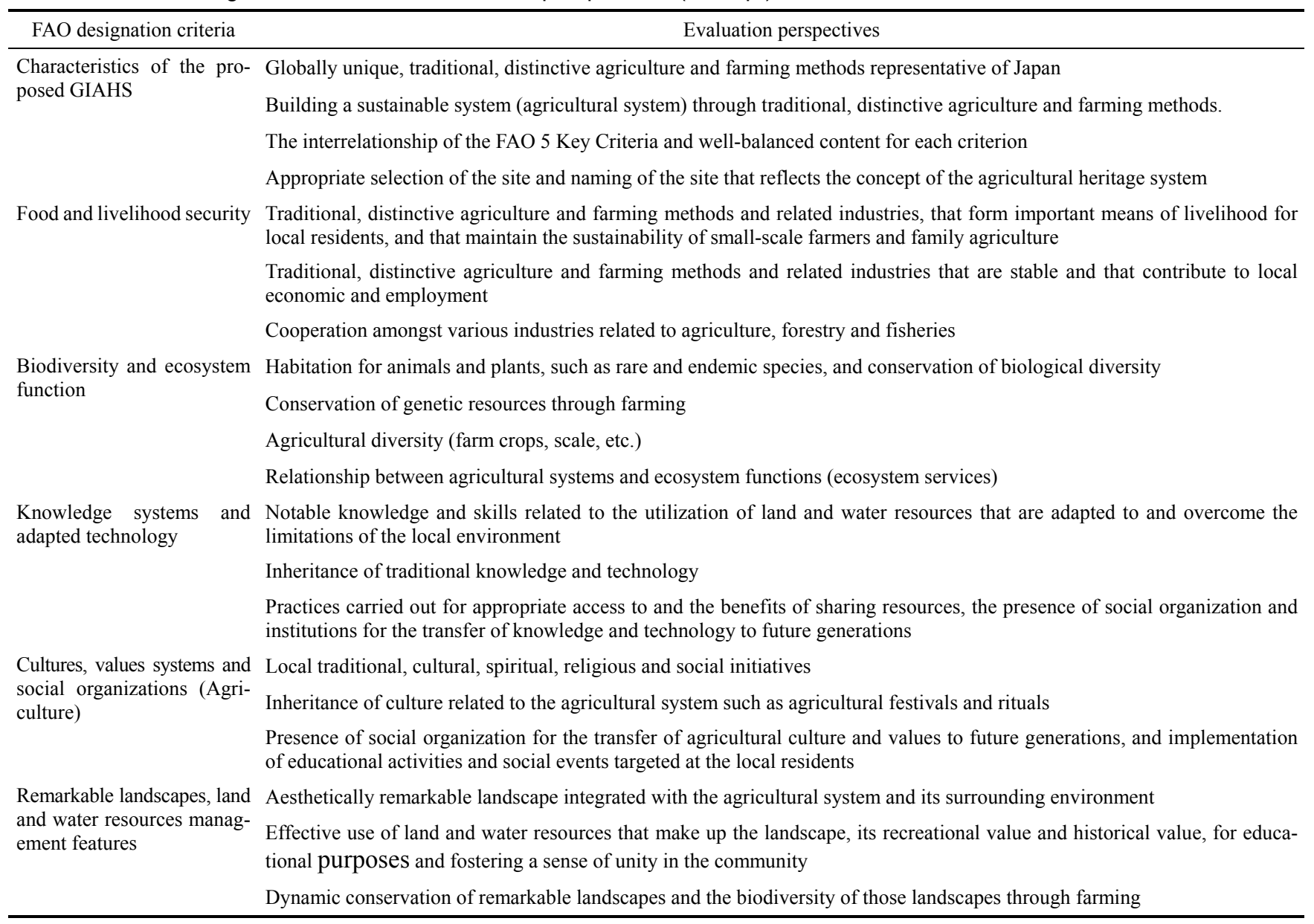

Source: Constructed by authors based on meeting documents of the MAFF GIAHS Experts Meeting

Table 3 GIAHS designation criteria and evaluation perspectives (Excerpt from "Points to be considered from the perspectives of Japan's agriculture")

\begin{tabular}{|c|c|}
\hline Points to be considered & Perspectives \\
\hline \multirow{3}{*}{$\begin{array}{l}\text { Resilience against change } \\
\text { (ecological aspects) }\end{array}$} & Capability of early recovery from natural disasters and changes in ecosystem of local traditional, ingenious farming systems \\
\hline & Capability of early recovery from natural disasters and changes in ecosystem that may arise in the future \\
\hline & $\begin{array}{l}\text { Mechanisms that ensure that the agricultural system is reliably inherited by future generations and conserved in face of natural } \\
\text { disasters and changes in ecosystem }\end{array}$ \\
\hline \multirow{2}{*}{$\begin{array}{l}\text { Participation by multiple } \\
\text { local stakeholders and pro- } \\
\text { moting institutions (soc- } \\
\text { ial aspects) }\end{array}$} & Participation of various local stakeholders and cooperation amongst these entities, including women and young people \\
\hline & Create conducive environment and initiatives to facilitate easy participation of various stakeholders \\
\hline \multirow{3}{*}{$\begin{array}{l}\text { New business models } \\
\text { (economic aspects) }\end{array}$} & Promotion of new business models associated with the agricultural system \\
\hline & Active inter-industry collaborations of agriculture, forestry and fisheries with other sectors such as tourism and service industries \\
\hline & Enhance branding of agriculture, forestry and fishery products \\
\hline
\end{tabular}

Source: Constructed by authors based on meeting documents of the MAFF GIAHS Experts Meeting

\subsection{Implementation Structure}

GIAHS is under the supervision of the MAFF Rural Development Bureau Rural Environment Division Biodiversity Conservation Office. This means that, in the case of Japan, GIAHS is positioned as part of the country's rural revitali- zation policy designed to conserve biodiversity. At the same time, the Biodiversity Conservation Office also works closely with the FAO liaison at International Affairs Department International Cooperation Division because GIAHS is a FAO initiative. Thus international meetings related to GIAHS are customarily attended by officers from both the 
Rural Development Bureau and the International Affairs Department.

Also, unlike China and Korea, Japan has not yet established its own national designation scheme for agricultural heritages. The reason for this seems to be a desire to prevent GIAHS from being just a passing interest and to maintain the high quality of GIAHS sites. Nonetheless, as the interest in applying for GIAHS rises, Japan must address the question of whether it needs its own national designation scheme from which to select GIAHS candidates, so as to expand the horizons of agricultural heritage and enable traditional agricultural systems to contribute effectively to rural revitalization. In fact, the MAFF GIAHS Experts Meeting proposed that Japan establish a national program for agricultural heritage in February 2016, and MAFF has accepted the recommendation and is currently formulating plans to implement a scheme in the near future.

\section{Nationally important agricultural and fis- hery heritage systems and GIAHS in Korea}

\subsection{Background of developments}

In Korea, the Korea Nationally Important Agricultural and Fishery Heritage Systems (hereafter referred to as Korea-NIAHS) was implemented in March 2012 before Korea's GIAHS designation by the then Ministry for Food, Agriculture, Forestry and Fisheries (or MIFAFF) (MIFAFF, 2012a). Korea-NIAHS is a national system to designate resources in rural areas that are in need of conservation, inheritance and utilization of agricultural and fisheries heritage so as to effectively utilize these resources by means of regional branding and tourism. It should be noted that MIFAFF was succeeded by Ministry of Agriculture, Food and Rural Affairs (MAFRA) for agriculture and forestry matters and Ministry of Oceans and Fisheries (MOF) for fisheries as part of the government's institutional restructuring in March 2013. As a result, the management of agricultural heritages, or National Important Agricultural Heritage Systems (NIAHS) falls under MAFRA and fishery heritages, or National Important Fishery Heritage Systems (NIFHS) under MOF. For simplicity's sake, both NIAHS and NIFHS will be collectively referred as KoreaNIAHS.

According to the MIFAFF press release dated April 4, 2012, agricultural and fishery heritages are creations of local people which have evolved over long period of times while adapting to changes in the environment. The press release stated that these traditional agriculture and fisheries systems and the landscapes formed by these systems are worth conserving and maintaining. The identification of Korea-NIAHS sites and an assessment process by researchers and a deliberative body of experts were undertaken in July 2012, after applications from municipalities were submitted to MIFAFF (in April). Unique heritage systems that are representative of Korea were then selected from among these Korea-NIAHS sites and submitted as candidates for FAO GIAHS application.
In December 2012, a MIFAFF notice announced that the "Guidelines of Management and Designation Criteria of Nationally Important Agricultural and Fishery Heritage Systems" had been enacted and was in force (MIFAFF, 2012b). Two Korea-NIAHS sites, "Traditional Gudeuljang Irrigated Rice Terraces in Cheongsando" in Wando, South Jeolla Province and "Jeju Batdam Agricultural System" in Jeju Province were then identified in January 2013 and subsequently also designated as Korea's first GIAHS sites at the FAO GIAHS Steering/Scientific Committee meeting held in Rome in April 2014.

In addition, two sites of "Gurae Cornelian Cherry Farming" and "Damyang Bamboo Field Landscape " in South Jeolla Province in June 2014, and two more sites of "Geumsan Ginseng Farming" in South Chungcheong Province and "Hadong Traditional Tea Farming " in South Gyeongsang Province were also identified as new NIAHS in March 2015. Three NIFHS sites of "Haenyeo Women Divers" in Jeju Province, "Boseong Mudboat Fishing" in South Jeolla Province and "Namhae Jukbangnyeom Fishing" in South Gyeongsang Province were officially designated as Korea's first NIFHS on 16 December 2015 (MOF,2015). Thus as of February 2016, Korea had a total of 6 NIAHS sites and 3 NIFHS sites.

It should be noted that "Special act on improving the quality of life for farmers and fishers and promoting development of rural areas" was amended in February 2015 in Korea. The conservation and utilization of Nationally Important Agriculture Heritage Systems (NIAHS) was added to Act 2 of Article 30, and conservation and utilization of Nationally Important Fishery Heritage Systems (NIFHS) was established in Act 3 of Article 30 (Korea National Legal Information Center, 2015). This law became effective from August 4, 2015, six months after its promulgation. This act was amended in view of the current challenges like industrialization and urbanization that threaten to damage or destroy agricultural heritage resources that are representative of farming culture formed over a long period of time. As a result of such challenges, there is a need to establish a management system to conserve and effectively utilize these valuable agricultural heritage resources by introducing appropriate measures to maintain the rural way of life and contribute to the rejuvenation of rural areas.

\subsection{Designation criteria}

Article 1 "General Provisions" of the "Guideline of Management and Designation Criteria of Nationally Important Agricultural and Fishery Heritage Systems" states that the purpose of the measures is to conserve the biodiversity of agricultural and fisheries heritage, and to improve the quality of life and revitalize rural areas. "Agricultural and fishery heritage" is defined as both tangible and intangible agricultural and fisheries systems that farmers and fishing people have built over a long period of time while adapting to the 
local environment, society and customs.

Article 2 "Selection of Nationally Important Agricultural and Fishery Heritage Systems" states that Korea-NIAHS sites (1) will possess multifaceted heritage resources with more than 100 years of tradition worthwhile for conservation, preservation and transfer to future generations, and (2) with special biodiversity characteristics with conservation, preservation and effective utilization value, that could be in tangible form, or a combination of tangible and intangible forms, or a combination of tangible/intangible forms with village, mountain and/or river landscapes. Worth noting here is that, while GIAHS is basically intended for agricultural systems, Korea-NIAHS also targets "tangible heritages". Thus in the selection criteria, it is specified that (1) the KoreaNIAHS should have inherent characteristics that have distinctive and historical value, (2) Korea-NIAHS sites and categories should be representative, (3) if the owner of a Korea-NIAHS exists, voluntary participation and agreement of the organization representative of the owner and local residents should be obtained, and (4) public order and morality should be upheld and in tune with public benefit. It is thus clear that a principal characteristic of Korea-NIAHS is that it includes the concept of ownership.

Moreover, in Article 4 of "Management of Nationally Important Agricultural and Fishery Heritage Systems", it is stipulated that (1) the mayor of the city or county that has jurisdiction over the Korea-NIAHS should establish a management plan, (2) as a general rule heritages should be managed by a residents' council including the owner, and (3) periodic monitoring and checks of the heritage should be conducted. Given the concept of "restoration and repair of heritage", it is assumed that the targeted heritage is a tangi- ble object.

The designation criteria for Korea-NIAHS is listed in Table 4 .

In addition to including FAO GIAHS criteria, it is notable that the Korea-NIAHS emphasizes multi-stakeholder participation by including partnerships as a key criterion. Other characteristics include an emphasis on improvement of brand value and regional image, and rural revitalization through enhancing rural-urban exchanges.

\subsection{Application procedure}

Under Article 3 "Agricultural and Fishery Heritage Council" of the "Guideline of Management and Designation Criteria of NIAHS", the Agricultural and Fishery Heritage Council shall be made up of core council members including the Director-General of Rural Policy Bureau, MAFRA, the Director of Rural Environment National Institute of Agricultural Sciences Korea Rural Development Administration, the Head of Rural Research Institute, Korea Rural Community Corporation, and not more than 20 commissioned council members. The council deliberates on matters related to selection of Korea-NIAHS. The commissioned members are specialists from various fields, including four members specializing in traditional culture, two in landscape, three in ecological environment, two in rural development, two in tourism and one in fisheries.

With regards to the details of the application procedure, Article 5 "Application for GIAHS" stipulates that the mayor of the city or county shall submit the explanatory documents, field survey report and application proposal. This will go through the provincial governor to Minister of MAFRA or Minister of MOF, and will be selected by the Agricultura

Table 4 The key criteria for Korea Nationally Important Agricultural and Fishery Heritage Systems

\begin{tabular}{|c|c|c|}
\hline Classification & Criteria & Features \\
\hline \multirow[t]{5}{*}{ Value of Heritage } & Historical Value & The agricultural-fishery activities of farmers or fishermen have more than 100 years of history \\
\hline & & Extent and sustainability of value projected into the future \\
\hline & Representativeness & Representative of the region and field; international, national and regional level of representation \\
\hline & & Possess remarkable landscape and has tourism, recreation and merchandizing potential \\
\hline & Characteristics & $\begin{array}{l}\text { Possess unique and striking features in the areas of land use and water resources management etc } \\
\text { (1-2 items of the following) } \\
\text { - Communal agro-fishery knowledge systems and technology } \\
\text { - Food or other products from agro-fishery activity } \\
\text { - Use of land and water resources and conservation of biodiversity, etc. }\end{array}$ \\
\hline \multirow[t]{2}{*}{ Partnership } & Cooperation & $\begin{array}{l}\text { Existence of a maintenance management plan from municipalities and residents indicating their } \\
\text { commitment to cost sharing, etc. }\end{array}$ \\
\hline & Participation & $\begin{array}{l}\text { Active participation and activities by community (including NGOs) for the preservation, mainte- } \\
\text { nance and transmission of the heritage }\end{array}$ \\
\hline \multirow{2}{*}{ Effectiveness } & Revitalization \& Biodiversity & $\begin{array}{l}\text { Ability to contribute to the local economy through urban and rural exchanges and increase in the } \\
\text { number of tourists upon the designation of the agricultural heritage }\end{array}$ \\
\hline & & $\begin{array}{l}\text { Improved biodiversity and the production of unique agricultural products as a result of traditional } \\
\text { farming methods. }\end{array}$ \\
\hline
\end{tabular}

Source: "Management standards for Agricultural and Fishery Heritage Systems" (MIFAFF Notice No. 2012-285, December 6, 2012) translated by authors 
1 Heritage Council for NIAHS or Fishery Heritage Council for NIFHS after deliberation.

\subsection{Implementation structure}

In Korea, the MAFRA Rural Policy Bureau Rural Development Division is in charge of agricultural heritages and the MOF Fisheries Infrastructure and Aquaculture Policy Bureau Fishing Community and Port Development Division is responsible for fishery heritages. However, the roles of international relations departments of these two groups is not well defined, and GIAHS-related international meetings are attended by rural development division officers but not officers in charge of FAO matters. Also, the groups involved with Korea's agricultural and fisheries include experts from regional development and rural planning, with each NIAHS or NIFHS site supported by its own group of experts. It remains to be seen how the management of both NIAHS and NIFHS will be coordinated between MAFRA and MOF, especially with regards to the selection of Korean candidate sites for applications of GIAHS designation. Korea NIFHS could also provide insights and perspectives pertinent to fisheries heritage for reference by FAO, where GIAHS designation of fisheries system has just started.

\section{Comparison of the agricultural heritage sy- stems of China, Japan and Korea}

A comparison of the agricultural heritage systems of China, Japan and Korea based on the background of developments, designation criteria, application procedure and implementation structure is presented in Table 5 .

\subsection{Background of developments}

China was the first to become involved with GIAHS in 2005, followed by Japan around 2010 and Korea in 2011. In China, Qingtian County of Zhejiang Province was first selected as a GIAHS pilot site in 2005 and subsequently China-NIAHS

Table 5 Comparison of the Agricultural Heritage Systems of China, Japan and Korea (based on developments as at February 2016)

\begin{tabular}{|c|c|c|c|}
\hline & China & Japan & Korea \\
\hline \multirow{7}{*}{$\begin{array}{l}\text { Background of } \\
\text { Developments }\end{array}$} & GIAHS: & GIAHS: & GIAHS: \\
\hline & First designation in 2005 & First designations in 2011 & 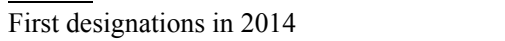 \\
\hline & 11 sites designated & 8 sites designated & 2 sites designated \\
\hline & China-NIAHS: & Japan-NIAHS: & Korea-NIAHS: \\
\hline & Implemented in 2012 & $\overline{\text { Not applicable }}$ & Implementation in 2012 \\
\hline & 62 sites designated & & Legal recognition in 2015 \\
\hline & & & 6 NIAHS sites, 3 NIFHS sites designated \\
\hline \multirow{7}{*}{$\begin{array}{l}\text { Designation Cri- } \\
\text { teria }\end{array}$} & Same as FAO GIAHS criteria & $\begin{array}{l}\text { In addition to FAO GIAHS criteria, } 3 \text { Jap- } \\
\text { anese perspectives } \\
\text { - Resilience to change, multi-stakehol- } \\
\text { ders participation, new business models } \\
\text { promotion }\end{array}$ & Same as Korea-NIAHS \\
\hline & China-NIAHS: & Japan-NIAHS: & Korea-NIAHS: \\
\hline & I. Basic Standards & $\overline{\text { Not applicable }}$ & I. Value of Heritage \\
\hline & $\begin{array}{l}\text { - Historical Value, Systemic, Persistency, } \\
\text { Endangered }\end{array}$ & & $\begin{array}{l}\text { - Historical Value, Representativeness, } \\
\text { Characteristics }\end{array}$ \\
\hline & II. Secondary Standards & & II. Partnership \\
\hline & - Demonstration, Supportability & & $\begin{array}{l}\text { - Cooperation, Participation, } \\
\text { III. Effectiveness }\end{array}$ \\
\hline & & & - Branding, Effective Use and Biodiversity \\
\hline \multirow{4}{*}{$\begin{array}{l}\text { Application Pro- } \\
\text { cedure }\end{array}$} & GIAHS: & GIAHS: & GIAHS: \\
\hline & $\begin{array}{l}\text { Governments at county level or above will } \\
\text { apply, through provincial agricultural ad- } \\
\text { ministrative departments, to the Interna- } \\
\text { tional Cooperation Division of Ministry of } \\
\text { Agriculture (MOA); selection by Experts } \\
\text { Committee }\end{array}$ & $\begin{array}{l}\text { Applications will be received and selected } \\
\text { by the Experts Meeting set up by the Min- } \\
\text { istry of Agriculture, Forestry and Fisheries } \\
\text { (MAFF) through first round of evaluation } \\
\text { and field survey and second round of eval- } \\
\text { uation }\end{array}$ & $\begin{array}{l}\text { Selected from Korea-NIAHS where the pro- } \\
\text { vincial governor will apply to Ministry of } \\
\text { Agriculture, Food and Rural Affairs (MA- } \\
\text { FRA) or Ministry of Oceans and Fisher- } \\
\text { ies(MOF), and be selected by the respective } \\
\text { Agricultural or Fishery Heritage Council }\end{array}$ \\
\hline & China-NIAHS: & Japan-NIAHS: & Korea-NIAHS: \\
\hline & $\begin{array}{l}\text { County level governments will apply, } \\
\text { through provincial agricultural administra- } \\
\text { tive departments, to Agricultural Products } \\
\text { Processing Bureau of MOA; selections } \\
\text { made by Experts Committee }\end{array}$ & Not applicable & $\begin{array}{l}\text { City or county mayors submit applications } \\
\text { to provincial governors who forward to } \\
\text { MAFRA or MOF; selections made by the } \\
\text { respective Agricultural and Fishery Heri- } \\
\text { tage Council }\end{array}$ \\
\hline Structure & $\begin{array}{l}\text { ral Resources Research at the Chinese } \\
\text { Academy of Sciences was the lead initially, } \\
\text { now GIAHS is under the supervision of } \\
\text { MOA International Cooperation Division } \\
\text { and China-NIAHS under MOA Agricul- } \\
\text { tural Products Processing Bureau }\end{array}$ & $\begin{array}{l}\text { Rural Development Bureau Biodiversity } \\
\text { Conservation Office, and coordination with } \\
\text { FAO is assisted by International Coopera- } \\
\text { tion Department }\end{array}$ & $\begin{array}{l}\text { velopment Division is in charge of both } \\
\text { GIAHS and NIAHS, while MOF Fisheries } \\
\text { Infrastructure and Aquaculture Policy Bu- } \\
\text { reau Fishing Community and Port Devel- } \\
\text { opment Division is responsible for NIFHS }\end{array}$ \\
\hline
\end{tabular}

Source: Created by authors based on related documents from China, Japan and Korea. 
was introduced in 2012. However, Korea was the opposite of China with Korea-NIAHS implemented first, followed by the effort to implement GIAHS. Moreover, in Korea, the National Important Agricultural Heritage Systems and Nationally Important Fisheries Heritage Systems were given legal status in August 2015. On the other hand, Japan has only GIAHS and has not implemented a national designation scheme as like NIAHS in China and Korea.

\subsection{Designation criteria}

As the selection of GIAHS sites in both China and Korea is based on consideration of the respective NIAHS sites, the designation criteria in both countries is a combination of FAO designation criteria and national criteria. In contrast, as Japan does not have a national designation scheme for agricultural heritages, but it does have the three Japanese perspectives when considering designations, but these are only for reference purposes.

\subsection{Application procedure}

In China, potential GIAHS sites were initially identified by experts in traditional agriculture. From 2012, since the national designation scheme for agricultural heritage systems was introduced, GIAHS candidate sites are now selected from among China-NIAHS sites. In Korea, the national designation scheme for agricultural heritage was implemented in 2012, and GIAHS candidate sites are selected from among the Korea-NIAHS sites. Japan was similar to that of China with experts (i.e. United Nations University), MAFF Regional Agricultural Administration Offices and municipal governments working together to identify GIAHS candidate sites beginning in 2010, but MAFF took over the application process beginning in 2014. In all three countries, a committee of experts has been formed to select NIAHS designated sites or GIAHS candidate sites. However, the size of the committees varies from 30 members from various fields in China to only seven members in Japan from specific areas of expertise; the number in Korea is in between those of China and Japan.

\subsection{Implementation structure}

While the departments in charge of NIAHS and GIAHS are separated in China, both NIAHS and GIAHS are under the supervision of MAFRA (NIFHS are under MOF) in Korea. In Japan, there is no department in charge of agricultural heritage at the national level since there is no NIAHS, but both the Rural Development and International Cooperation Departments of MAFF are promoting GIAHS together.

\subsection{Other observations}

China, Japan and Korea have markedly different ideas concerning financial support and regulatory measures for GIAHS designated sites. In China and Korea, certain financial support will be given to the GIAHS designated sites, while in
Japan specialized financial support for GIAHS is very limited, although GIAHS designated sites will receive general budgetary support. In China and Korea, GIAHS are subject to certain regulatory measures while in Japan GIAHS sites are not subject to GIAHS specific regulatory measures, but only to general regulatory measures.

\section{Conclusions}

In this paper, an attempt has been made to compare the agricultural heritage conservation schemes of China, Japan and Korea. Through this comparison, the background, designation criteria, application procedures and implementation structures of GIAHS have been made clear against a background of differences in national circumstances in the three countries. At the same time, with regards to their respective designation criteria, commonalities can be seen. Thus, cooperation amongst China, Japan and Korea will be an important means to advance proposals to improve the FAO designation criteria for GIAHS in ways that make the criteria more broadly applicable to both developing and developed countries. An assessment of conditions in developing countries was the primary consideration in the design of current GIAHS designation criteria.

In fact, the cooperation amongst these three countries is already underway, and an important milestone was marked with an agreement to establish the East Asia Research Association for Agricultural Heritage Systems (ERAHS) reached on October 2013. The first ERAHS conference took place in April 2014 in Xinghua City, Jiangsu Province of China and the second ERAHS Conference was held in Sado City of Japan in June 2015. The third conference is scheduled to take place in Geumsan County of Korea in June 2016. Although some deep-rooted political and diplomatic differences between the three countries remain, there is hope that platforms such as the agricultural heritage systems will allow these countries to share, understand and learn from one another and forge stronger ties of mutual cooperation. Moreover, it is hoped that the close cooperation of China, Japan and Korea will help the GIAHS network, which is currently concentrated in East Asia, to expand to other countries in Asia, Africa, Latin America and even to developed Western nations, so as to strike a geographical balance to better capture the important agricultural heritages in the world.

\section{Acknowledgments}

This paper is based in part on the research outcomes of the "Developing a Comprehensive Assessment Methodology for AgriCultural Systems in Japan (ACS)" project funded by Japan Ministry of Agriculture, Forestry and Fisheries (MAFF) Policy Research Institute. The authors would like to express their heartfelt gratitude to MAFF for this invaluable research opportunity for the ACS project and also to all others in China, Japan and Korea who assisted and supported them in completing the research for this paper. 


\section{References}

Korea Ministry of Fisheries. 2015. "Designation of the world's first traditional fishery system, national important fishery heritage." 16 December 2015. (in Korean). http://www.mof.go.kr/article/view.do? men$\mathrm{uKey}=376 \&$ boardKey $=10 \&$ articleKey $=10322$

Ministry of Agriculture of the People's Republic of China. 2015. "Circular of the Ministry of Agriculture on the list of third batch of important agricultural heritage systems of China." 10 October 2015. (in Chinese). http://www.moa.gov.cn/zwllm/tzgg/tz/201510/t20151012_4861519.htm

Takeuchi, Kazuhiko and Nagata Akira. 2015. GIAHS - Passing on traditional agriculture to the future generations. Ningenkagi, Summer 2015: 179-185. ( in Japanese)

Korea National Legal Information Center. 2015. Special act on improving the quality of life for farmers and fishers and promoting development of rural areas. 3 February 2015. (in Japanese). http://law.go.kr/LSW/nwRvsLsInfoR.do?lsiSeq=167992\&lsKndCd=A0002

Food and Agriculture Organization of the United Nations. 2014. "Globally Important Agricultural Heritage Systems." Programme and Finance Committee. http://www.fao.org/3/a-ml938e.pdf

Ministry of Agriculture of the People's Republic of China. 2014. "Circular of the General Office of the Ministry of Agriculture on printing and distributing the Administrative Measures on National Important Agricultural Heritage Systems(Trial).” 21 May 2014. (in Chinese). http://www. moa.gov.cn/sjzz/qiyeju/dongtai/201406/t20140612_3937353.htm

Ministry of Agriculture of the People's Republic of China. 2014. "The Establishment of the Ministry of Agriculture Globally Important Agricultural Heritage Systems Experts Committee." 16 January 2014. (in Chinese).http://www.moa.gov.cn/sydw/nybgjjlfwzx/nywhyc/gzdt/ 201407/ t20140722_4010722.htm

Ministry of Agriculture of the People's Republic of China. 2014. "Circular of the Ministry of Agriculture on releasing second batch of National Important Agricultural Heritage Systems." Gazette of the Ministry of Agriculture of the People's Republic of China, 21 May 2014: P2627. (in Chinese). http://www.moa.gov.cn/zwllm/tzgg/gb/nybgg/201406/ P020140626583619145921.pdf

Ministry of Agriculture of the People's Republic of China. 2014. "Circular of the General Office of the Ministry of Agriculture on discovering and exploiting third batch of important agricultural heritage systems of China." 27 May 2014. (in Chinese). http://www.xqj.moa.gov.cn/dongtai/ 201406/ t20140612 3937390.htm

Japan Ministry of Agriculture, Forestry and Fisheries. 2014. "The estab- lishment of Globally Important Agricultural Heritage Systems (GIAHS) Experts Meeting.”24 March 2014. (in Japanese). http://www.maff.go.jp/ $\mathrm{j} /$ nousin/kantai/pdf/ secchi.pdf

Ministry of Agriculture of the People's Republic of China. 2013. "Circular of the General Office of the Ministry of Agriculture on printing and distributing two documents as A Guide to Filing Application for Induction into List of National Important Agricultural Heritage Systems (NIAHS) and A Guide to Planning of Conservation and Inheritance of Agricultural Heritage Systems." 2 July 2013. (in Chinese). http:// www.moa.gov.cn/sjzz/qiyeju/dongtai/201307/t20130708_3516003.htm

Ministry of Agriculture of the People's Republic of China. 2013. "Circular of the Ministry of Agriculture on the list of third batch of important agricultural heritage systems of China." 2 May 2013. (in Chinese). http://www.moa.gov.cn/zwllm/zxfb/ 201305/t20130502 3449361.htm

Korea Ministry for Food, Agriculture, Forestry and Fisheries. 2012. "Official Introduction of Agriculture and Fisheries Heritage System by Ministry for Food and Agriculture." 4 April 2012. (in Korean) http://www mafra.go.kr/list.jsp?\&newsid=155442650\&section_id=b_sec_1\& pageNo= $287 \&$ year $=2015 \&$ listcnt $=10 \&$ board_kind $=$ C\&board_skin_id $=C 3 \& d e p t$ $\mathrm{h}=\&$ division $=\mathrm{B} \&$ group_id $=3 \&$ menu_id $=1125 \&$ reference $=2 \&$ parent_co $\mathrm{de}=3 \&$ popup_yn $=\mathrm{N} \& \mathrm{tab} \_\mathrm{yn}=\mathrm{N}$

Korea Ministry for Food, Agriculture, Forestry and Fisheries. 2012. "Guideline of Management and Designation Criteria of Nationally Important Agricultural and Fishery Heritage Systems." 6 December 2012 (in Korean). http://law.go.kr/LSW/admRulLsInfoP. do?admRulSeq= 2000000021648

Institute of Geographic Sciences and Natural Resources Research, Chinese Academy of Sciences. 2012. "Recapturing the developments of the implementation of GIAHS project and conservational activities of agri-cultural heritage in China." Newsletter of Agri-Cultural Heritage Systems, Volume 1, 2012:51-57. (in Chinese)

Ministry of Agriculture of the People's Republic of China Bureau of Produce Processing. 2012. "Circular of the Ministry of Agriculture on discovering and exploiting important agricultural heritage systems of China" 20 March 2012. (inChinese). http://www.xqj.moa.gov.cn/xxny/ 201204/t20120423_2608050.htm

Food and Agriculture Organization of the United Nations. 2012. "GIAHS Partnership Framework (as of 26 October 2012)." GIAHS Scientific and Steering Committee Meeting, Rome, 29-30 October 2012.

Nagata, Akira. 2011. Farming rural areas and biodiversity - the activities of United Nations University in cooperation with Japan Ministry of Agriculture, Forestry and Fisheries. ARDEC. 44: 8-12.

\title{
中日韩三国农业文化遗产保护比较研究
}

\author{
姚盈芳 ${ }^{1}$ ，永田明 ${ }^{1}$ ，武内彦和 ${ }^{2}$ \\ 1 联合国大学持续可能性高等研究所, 东京 $150-8925$, 日本; \\ 2 联合国大学, 东京 $150-8925$, 日本
}

摘 要: 本文对中国、日本和韩国的农业文化遗产保护计划, 特别是在联合国粮农组织(FAO)全球重要农业文化遗产(GIAHS) 项目和国家计划实施之下的保护与发展工作进行了比较分析。研究表明, 中日韩三国的GIAHS实践和国内制度推行的发展历程、 认定标准、申请程序以及实施架构等方面显示出国情背景间的差异。例如，在推行GIAHS实践和国内制度的时间顺序上三国各不 相同。中国在GIAHS认证数年后推出国家认定制度，日本目前只有GIAHS没有国家认定制度，而韩国在GIAHS认证之前已实施国 家认定制度。因此，目前中国和韩国的GIAHS候选地是从国内认定的农业文化遗产地挑选出来的。另一方面，从认定标准可以看 出中日韩三国对于农业文化遗产保护的理念有共同点, 均重视农业遗产系统相关的历史意义、文化价值、合作互促、农村振兴、 生物多样性保护等。因此, 中日韩三国间的紧密合作以及他们的观点将对改进FAO的GIAHS认定标准、促进其更全面地适用于发 展中国家和发达国家起到重要作用。

关键词：农业遗产系统；全球重要农业文化遗产(GIAHS)；传统农业；农村振兴；生物多样性保护；东亚 